\title{
Clinical characteristics and Outcomes of 500 patients with COVID Pneumonia - Results from a Single center (Southend University Hospital).
}

\author{
Gouri Koduri $^{2,}$ Sriya Gokaraju ${ }^{1}$, Maria Darda ${ }^{1}$, Vinod Warrier $^{3}$, Irina Duta ${ }^{3}$, Fiona Hayes ${ }^{2}$, \\ Iman El Sayed ${ }^{4}$, Yasser Ahmed ${ }^{1}$
}

\section{Affiliations}

1. Respiratory Department - Mid \& South Essex NHS Foundation Trust, Southend University Hospital, Westcliff-on-Sea, Essex, UK

2. Rheumatology department - Mid \& South Essex NHS Foundation Trust, Southend University Hospital, Westcliff-on-Sea, Essex, UK

3. Department of Medicine - Mid \& South Essex NHS Foundation Trust, Southend University Hospital, Westcliff-on-Sea, Essex, UK

4. Iman El Sayed - Biomedical Informatics and Medical Statistics Department, Medical Research Institute, Alexandria University, Alexandria, Egypt

Correspondence: Gouri Koduri, Rheumatology, Mid \& South Essex NHS Foundation Trust, Southend University Hospital, Westcliff-on-Sea, Essex, UK

E-mail: gouri.koduri@southend.nhs.uk

\section{Key words:}

COVID-19, Epidemiological characteristics, Sars-Cov-2, prognostic factors

\begin{abstract}
:
\section{Objectives}

To characterise the clinical features of hospitalised COVID-19 patients in a single centre during the first epidemic wave and explore potential predictive variables associated with outcomes such as mortality and the need for mechanical ventilation, using baseline clinical parameters.
\end{abstract}

\section{Methodology}

We conducted a retrospective review of electronic records for demographic, clinical and laboratory data, imaging and outcomes for 500 hospitalised patients between February $20^{\text {th }}$ and May $7^{\text {th }} 2020$ from Southend University Hospital, Essex, UK. Multivariate logistic regression models were used to identify risk factors relevant to outcome.

Results

The mean age of the cohort admitted to hospital with Covid-19, was 69.4 and 290 (58\%) were over 70. The majority were Caucasians, 437 (87\%) with $\leq 2$ comorbidities $280(56 \%)$. Most common were hypertension 186(37\%), Cardiovascular disease 178(36\%) and Diabetes $128(26 \%)$, represented in a 
larger proportion on the mortality group. Mean CFS was 4 with Non - Survivors had significantly higher CFS 5 vs 3 in survivors, $p<0.001$. In addition, Mean CRP was significantly higher 150 vs 90, $\mathrm{p}<0.001$ in Non-Survivors. We observed the baseline predictors for mortality were age, CFS and CRP.

\section{Conclusions}

In this single centre study, older and frailer patients with more comorbidities and a higher baseline CRP and creatinine were risk factors for worse outcomes. Integrated frailty and age-based risk stratification are essential, in addition to monitoring SFR (Sp02/Fi02) and inflammatory markers throughout the disease course to allow for early intervention to improve patient outcomes.

\section{Introduction:}

The COVID-19 pandemic is one of the worst infectious disease outbreaks of recent times; with the first wave in the UK, we have encountered 312,000 confirmed cases and 44,819 fatalities ${ }^{1}$. The pandemic coronavirus disease 19 (COVID-19) is characterized by a highly variable course. While most patients experience only mild symptoms, a relevant proportion of patients develop severe disease progression up to respiratory failure. Several factors and mechanisms are proposed to influence COVID-19 pathogenesis. The most notable risk factor is age, followed by co-morbidities, including diabetes, obesity, cardiovascular and cerebrovascular diseases ${ }^{2-5}$.

The mortality rate is variable; this is because of differences in the population demographics, the ascending curve, the method used to register COVID-19, and the health services ${ }^{6}$. A recent report showed that mortality rate was $5.6 \%$ for China and $15.2 \%$ outside of $\mathrm{China}^{7}$. Belgium has relatively high case fatality rates (16.34\%), followed by France (15.65\%), UK (14.21\%), Italy (14.15\%), Hungary (13.07\%), Netherlands (12.91\%), Sweden (12.21\%) and USA (5.95\%). The mortality excess has been primarily seen in the age group of $\geq 65$ years globally with higher case fatality rates(CFR) in older patients with comorbidities ${ }^{8,9}$

We have analysed clinical characteristics and prognostic factors that may be pertinent to patient outcomes, describing measures that have not been extensively described in existing literature such as the Clinical Frailty Scale (CFS), an efficient tool for assessing frailty, since this may be significant in determining outcomes for older patients ${ }^{10}$. We hope that by adding to this growing body of evidence identifying potential predictive variables in outcomes - we can assist early intervention in these patients in order to prevent rapid clinical deterioration and offer medications that have shown evidence in improving outcomes ${ }^{11,12}$. 


\section{Methodology:}

In this retrospective study, 500 patients with COVID-19 infection who were admitted to Southend University Hospital from $20^{\text {th }}$ February to $7^{\text {th }}$ May 2020 were enrolled. Demographic variables collected were age, sex, and ethnicity. Clinical signs and symptoms included categorical and continuous variables, baseline vitals and symptoms. Imaging results comprised chest radiography (CXR) abnormality and computed tomographic (CT) imaging. SP02 to Fi02 ratio (SFR) was calculated in addition to baseline partial arterial oxygen pressure ( $\mathrm{PaO} 2$ ). Laboratory findings comprised full blood count, neutrophil to lymphocyte ratio (NLR), C - reactive protein and renal function.

A number of comorbidities and comorbidities of particular interest including pulmonary disease, diabetes, hypertension, coronary artery disease, cerebrovascular disease, cancer and chronic renal disease were recorded. We also collected data on degree of frailty, using the Rockwood Clinical Frailty Scale (CFS) on all patients, outcomes, total length of stay (LOS) and need for mechanical ventilation. We analysed the demographic, clinical, laboratory and imaging features of 500 patients with COVID-19 to determine potential biomarkers that may affect the prognosis of these patients.

\section{Statistical analysis:}

The baseline characteristics of all enrolled patients in survivor and non-survivor groups were summarized and compared by applying Student's $t$ test, the Chi-square test, and the Mann-Whitney $U$ test as appropriate. We did not calculate sample size prior to conducting our study. However, based on a rule of thumb, we achieved a minimum required sample size for the development of the model based on the need for 10-15 non-survived patients per risk factor ${ }^{13}$.

Quantitative data were described by mean (standard deviation) and median (minimum-maximum). Categorical variables were summarized by frequency and percent. Bivariate analysis using Independent sample t-test, Mann-Whitney test as well as Pearson's Chi-square test compared different demographic and clinical parameters between survivors and non-survivors. Statistically significant and clinically relevant predictors were fitted in multivariate stepwise backward logistic regression analysis. Variables initially included were age, gender, CFS, Comorbidities $>2$, NLR, CRP, creatinine, RR, CPAP, SFR, Total LOS and interaction CPAP*CFS. Model selection was judged by goodness of the fit using Likelihood Ratio Test as well as pseuso ${ }^{2}$. Model cross-validation was performed by randomly splitting the sample into development and test sets (ratio 3:1). The prognostic ability of the model was determined by calculating the accuracy of model's predicted probability as well as the area under the receiver operating characteristics curve (AUROC) on the test set. Statistical analysis was performed using IBM SPSS statistics program and R software packages "caTools", "Imtest", "caret", "ROCR" and" ggplot2". All statistical tests were two-sided and judged at 0.05 significance level.

Results: The demographic and clinical parameters of the cohort, Survivors and Non survivors are shown in Table 1.

Cough and dyspnoea were the most common presentation with equal representation $294(60.2 \%)$

followed by fever $247(49.5 \%)$, GIT symptoms $98(19.9 \%)$, falls $65(13 \%)$ and confusion $47(9.4 \%)$. Falls 
and confusion were common in elderly patients. Majority of the cohort was Caucasian, $438(87.6 \%)$ and age $>70$ were 291 (58.9\%).

Of the 500 patients $193(38.6 \%)$ died. There was male preponderance among Non - Survivors $128(66.3 \%)$ and were much older (77.4 vs 64.5 years, $P<0.001)$ and presented with more comorbidities, including Diabetes (65 [33.7\%] vs. 63 [20.6\%], $P=0.001$ and Cardiovascular disease (95 [49.2\%] vs. 83 [27.1\%], $P<0.001$ ). Proportion of deaths with $\mathrm{PaO}_{2} / \mathrm{FiO}_{2}$ less than 336 (mean) was statistically significantly $(p<0.001$ ). As per ARDS criteria, Non-Survivors had lower SFR $315, p<$ 0.001 . Non-Survivors were more tachypnoeic, Respiratory rate $>24, p<0.001$.

Clinical Frailty Scale: Mean CFS was 4, However compared to survivors of COVID- 19, Non - Survivors had significantly higher CFS 3 vs $5, p<0.001$.

A number of laboratory parameters showed significant differences among Survivors and NonSurvivors.

Table 2. Mean CRP was significantly higher 150 vs $90, p<0.001$ in Non-Survivors, as well as Neutrophil count 7.84, $p<0.001$, Urea 12.71, $p<0.001$ and creatinine 136, $p=0.001$.CXR abnormalities were observed more in Non survivors and supplemental Oxygen requirement was higher in NonSurvivors $181(93.8 \%)$ as compared to Survivors $165(53.9 \%), p<0.001$.

There were no statistical differences on length of stay, need for mechanical ventilation or symptoms between the two groups.

Predictors for Mortality, Multivariate Analysis: Next, we examined the variables which showed a significant correlation with negative outcomes in the multivariate logistic regression models to identify if these were independent predictors for mortality.

In the stepwise logistic regression models, the following were independent risk factors for mortality in model 1, age adjusted OR $1.035(95 \% \mathrm{Cl} 1.012-1.058$ ), NLR adjusted OR 1.021 ( $95 \% \mathrm{Cl} 1.00-$ 1.04), CFS adjusted OR 1.132(95\% Cl $1.13-1.53$ ) and CRP adjusted OR 1.006(95\% Cl 1.003-1.009), (Table 3 and figure 1a). Again in model 2, age and CFS score were strong risk factors. Interestingly gender didn't reach the statistical significance for mortality. Similarly creatinine, SFR and CXR abnormalities did not reach statistical significance but had a trend towards increased mortality (Table 3 and fig $1 \mathrm{~b}$ ).

\begin{tabular}{|c|c|c|c|c|}
\hline Variables & Total & $\begin{array}{l}\text { Survivors } \\
\text { (n=307) }\end{array}$ & $\begin{array}{c}\text { Non-survivors } \\
\quad(n=193)\end{array}$ & Sig \\
\hline & 500 & & & \\
\hline Male & $300(60)$ & $172(56)$ & $128(66.3)$ & p. $022 *$ \\
\hline Female & $200(40)$ & $135(44)$ & $65(33.7)$ & \\
\hline Age, mean (SD) & $69.39(17.2)$ & $64.5(18.3)$ & $77.4(11.6)$ & $\mathrm{P}<.001^{*}$ \\
\hline median (min-max) & $73(19-100)$ & $68(19-100)$ & $78(37-99)$ & \\
\hline$<40$ & $36(7.2)$ & $35(11.4)$ & $1(0.5)$ & \\
\hline $40-70$ & $173(34.6)$ & $131(42.7)$ & $42(21.8)$ & $\mathrm{P}<.001^{*}$ \\
\hline $70-80$ & $132(26.4)$ & $67(21.8)$ & $60(33.7)$ & \\
\hline$>80$ & $159(31.8)$ & $74(24.1)$ & $85(44)$ & \\
\hline Ethnicity Asian & $31(6.2)$ & $24(7.8)$ & $7(3.6)$ & p.255 \\
\hline Black-African & $21(4.2)$ & $12(3.9)$ & $9(4.7)$ & \\
\hline
\end{tabular}




\begin{tabular}{|c|c|c|c|c|}
\hline Caucasian & $438(87.6)$ & $264(86)$ & $174(90.2)$ & \\
\hline Other & $10(2)$ & $7(2.3)$ & $3(1.6)$ & \\
\hline \multicolumn{5}{|l|}{ Comorbidities None } \\
\hline$<2$ & $282(56.4)$ & $203(66.1)$ & $79(40.9)$ & $\mathrm{P}<.001^{*}$ \\
\hline$>2$ & $218(43.6)$ & $104(33.9)$ & $114(59.1)$ & \\
\hline DM & $128(25.7)$ & $63(20.6 \%)$ & $65(33.7 \%)$ & p.001* \\
\hline Hypertension & $188(37.8)$ & $108(35.3)$ & $80(41.7)$ & p.153 \\
\hline Cardiovascular disease & $178(35.7)$ & $83(27.1)$ & $95(49.2)$ & $\mathrm{P}<.001^{*}$ \\
\hline Cerebrovascular disease & $44(8.8)$ & $28(9.2)$ & $16(8.3)$ & p.741 \\
\hline Respiratory disease & $148(29.7)$ & $100(32.7)$ & $48(24.9)$ & p.063 \\
\hline Other & $281(56 \%)$ & $151(49.3)$ & $132(68.4)$ & $\mathrm{P}<.001^{*}$ \\
\hline CFS, median (min-max) & $4(1-9)$ & $3(1-9)$ & $5(1-9)$ & $\mathrm{P}<.001^{*}$ \\
\hline Respiratory rate $\geq 24$ & $271(54.2)$ & $140(45.6)$ & $131(67.9)$ & $\mathrm{P}<.001^{*}$ \\
\hline Heart rate $\quad>100$ & $175(35)$ & $100(32.6)$ & $74(38.9)$ & p.151 \\
\hline Temp & $256(51.2 \%)$ & & & \\
\hline SFR, mean (SD) & $383.5(106.8)$ & $413.0(76.6)$ & $336.8(129.1)$ & $\mathrm{P}<.001^{*}$ \\
\hline SFR $<235$ & $52(10.4)$ & $12(3.9)$ & $40(20.7)$ & \\
\hline SFR <315(235-315),ARDS & $51(10.2)$ & $21(6.8)$ & $30(15.5)$ & $\mathrm{P}<.001^{*}$ \\
\hline $\begin{array}{l}\text { SFR } \geq 315 \text {, acute lung } \\
\text { injury }\end{array}$ & $397(79.4)$ & $274(89.3)$ & $123(63.7)$ & \\
\hline Symptoms Cough & $294(60.2)$ & $186(62)$ & $108(57.4)$ & p.317 \\
\hline SOB & $294(60.2)$ & $177(59)$ & $117(62.2)$ & p.447 \\
\hline Sore throat & $32(6.5)$ & $23(7.6)$ & $9(4.8)$ & p.214 \\
\hline GI & $98(19.9)$ & $67(22.2)$ & $31(16.3)$ & p.112 \\
\hline Fever & $247(49.5)$ & $158(51.6)$ & $89(46.1)$ & p.230 \\
\hline Lethargy & $52(10.4)$ & $32(10.5)$ & $20(10.4)$ & p.973 \\
\hline Falls & $65(13)$ & $37(12.1)$ & $28(14.5)$ & p.435 \\
\hline Myalgia & $20(4)$ & $15(4.9)$ & $5(2.6)$ & p.200 \\
\hline Confusion & $47(9.4)$ & $24(7.8)$ & $23(11.9)$ & p.129 \\
\hline
\end{tabular}

[? Comorbidities of interest have been selected. SFR is categorised by American European consensus

Table 2: Baseline Clinical parameters

\begin{tabular}{lllll} 
Variables & Total & Survivors & Non-survivors & Sig \\
CRP, mean (SD) & $114.19(91.26)$ & $90.64(82.18)$ & $150.27(93)$ & $\mathrm{P}<.001^{*}$ \\
Lymphocyte, mean (SD) & $1.37(4.56)$ & $1.35(3.8)$ & $1.39(5.5)$ & .925 \\
Neutrophil, mean (SD) & $6.88(4.8)$ & $6.29(4.3)$ & $7.84(5.42)$ & $\mathrm{P}<.001^{*}$ \\
NL Ratio, mean (SD) & $12.56(24.5)$ & $10.62(27.86)$ & $15.65(17.72)$ & $\mathrm{p} .027^{*}$ \\
Urea, mean (SD) & $9.88(8.92)$ & $8.06(7.98)$ & $12.71(9.58)$ & $\mathrm{P}<.001^{*}$ \\
Creatinine, mean (SD) & $114.65(107.8)$ & $100.89(93.31)$ & $136.05(124.40)$ & $\mathrm{P} .001^{*}$ \\
CXR, $\mathbf{n}(\%)$ & & & & \\
Not done & $28(5.6 \%)$ & & & \\
$\mathbf{1}$ & $140(29.7)$ & $103(36)$ & $37(19.9)$ & \\
$\mathbf{2}$ & $317(67.2)$ & $177(61.9)$ & $140(75.3)$ & $\mathrm{P}<.001^{*}$ \\
$\mathbf{3}$ & $15(3.2)$ & $6(2.1)$ & $9(4.8)$ & \\
CT Scan Not done, $\mathrm{n}(\%)$ & $397(79.4 \%)$ & & & \\
\multicolumn{1}{r}{ Covid } & $103(20.6 \%)$ & & &
\end{tabular}


medRxiv preprint doi: https://doi.org/10.1101/2020.08.13.20163030; this version posted August 14, 2020. The copyright holder for this preprint (which was not certified by peer review) is the author/funder, who has granted medRxiv a license to display the preprint in perpetuity.

All rights reserved. No reuse allowed without permission.

\begin{tabular}{|c|c|c|c|c|}
\hline \multicolumn{5}{|l|}{ Blood cultures, n (\%) } \\
\hline Gram positive & $34(6.8 \%)$ & $16(11.2)$ & $18(14.8)$ & \multirow[t]{4}{*}{ p.652 } \\
\hline Gram negative & $10(2.0 \%)$ & $6(4.2)$ & $4(3.3)$ & \\
\hline No growth & $221(83.4)$ & $121(84.6)$ & $100(82)$ & \\
\hline Not done & $235(47)$ & & & \\
\hline \multicolumn{5}{|l|}{$\mathbf{N}(\%)$} \\
\hline Oxygen requirement & $346(69.3)$ & $165(53.9)$ & $181(93.8)$ & $\mathrm{P}<.001^{*}$ \\
\hline CPAP & $56(11.2 \%)$ & $36(11.7)$ & $20(10.4)$ & p.638 \\
\hline Mechanical ventilation & $64(12.8 \%)$ & $36(11.7)$ & $28(14.5)$ & p.365 \\
\hline Length of stay, mean (SD) & $9.33(12.17)$ & $9.51(14.01)$ & $9.05(8.5)$ & p.677 \\
\hline Total IMV days, mean (SD) & $14.5(12.31)$ & $17.62(14)$ & $10.60(8.55)$ & p.023* \\
\hline SFR, mean (SD) & $383.65(106.81)$ & $413.08(76.68)$ & $336.82(129.19)$ & $\mathrm{P}<.001^{*}$ \\
\hline Baseline Fio2, mean (SD) & $.46(4.19)$ & $.54(5.53)$ & $.35(.23)$ & p.615 \\
\hline Baseline $\mathrm{S} 02$, mean (SD) & $91.92(8.61)$ & $93.29(8.08)$ & $89.75(9)$ & $\mathrm{P}<.001^{*}$ \\
\hline$R R$, mean (SD) & $25.75(8.29)$ & $24.29(7.44)$ & $28.07(9.03)$ & $\mathrm{P}<.001 *$ \\
\hline
\end{tabular}

${ }^{*}$ results $\leq .05$ are significant by either independent sample t test, Mann-Whitney test for CFS and Chi-square test for categorical variables .CXR $1=$ Indeterminate, CXR $2=$ Classic/Moderate, CXR $3=$ Severe COVID changes
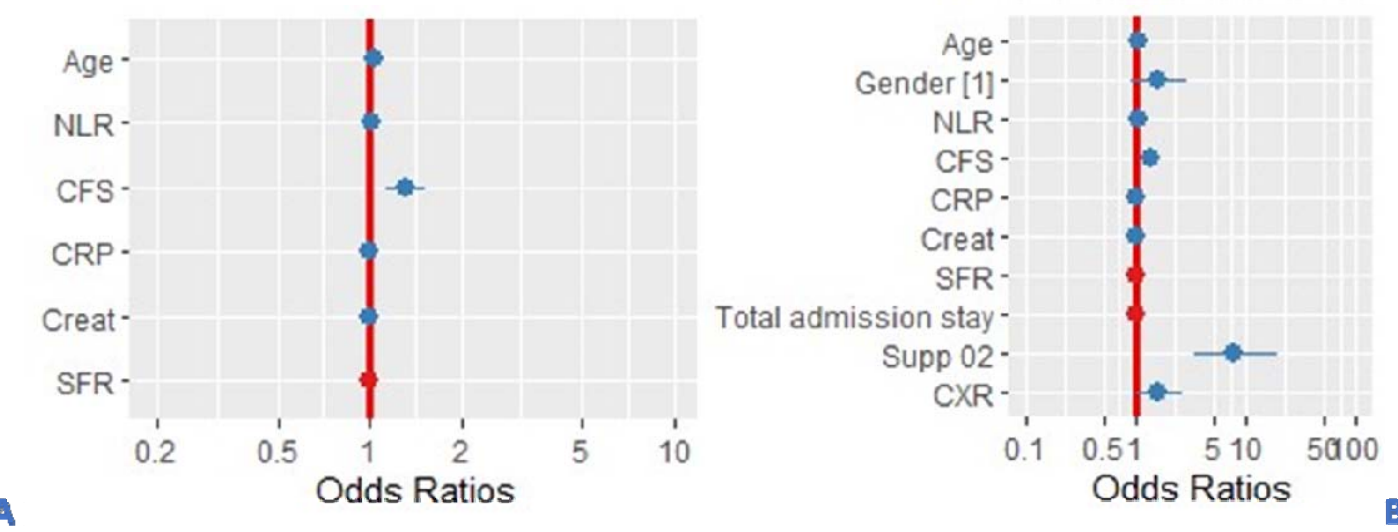

Figure (1): Adjusted Odds ratio calculated from multivariate stepwise logistic regression analysis for assessing independent predictors of mortality.

A: model1, B: model2. Likelihood Ratio Test for comparison of goodness of fit between model 1 and 2 revealed better performance in favour of model $2\left(x^{2}=35.8, p<.001 *\right)$ 
Table 3: Multivariate logistic regression analysis for assessing independent predictors for mortality.

$\begin{array}{cccc}\begin{array}{l}\text { Regression } \\ \text { coefficient }\end{array} & \text { Sig } & \begin{array}{c}\text { Unadjusted OR } \\ (95 \% \mathrm{Cl})\end{array} & \begin{array}{c}\text { Adjusted OR } \\ (95 \% \mathrm{Cl})\end{array}\end{array}$

\section{Model1}

\begin{tabular}{lcccc|} 
Age & 0.034 & $.002^{*}$ & $1.05(1.03-1.06)$ & $1.035(1.012-1.058)$ \\
NLR & 0.021 & $.024^{*}$ & $1.04(1.02-1.06)$ & $1.021(1.00-1.04)$ \\
CFS & 0.277 & $<.001^{*}$ & $1.45(1.30-1.62)$ & $1.132(1.13-1.53)$ \\
CRP & 0.006 & $<.001^{*}$ & $1.006(1.004-1.009)$ & $1.006(1.003-1.009)$ \\
Creatinine & 0.002 & .070 & $1.004(1.001-1.008)$ & $1.002(.999-1.005)$ \\
SFR & 0.004 & $<.001^{*}$ & $.993(.990-.995)$ & $.995(.993-.998)$ \\
Constant & -3.867 & $<.001^{*}$ & & $.020(0-.01)$
\end{tabular}

Model2:

$\begin{array}{lcccc}\text { Age } & .037 & <.001^{*} & 1.05(1.03-1.06) & 1.038(1.013-1.063) \\ \text { Male gender } & .459 & .113 & & 1.583(.896-2.797) \\ \text { NLR } & .019 & .050 & 1.04(1.02-1.06) & 1.019(.999-1.039) \\ \text { CFS } & .305 & <.001^{*} & 1.45(1.30-1.62) & 1.356(1.145-1.606) \\ \text { CRP } & .005 & <.001^{*} & 1.006(1.004-1.009) & 1.006(1.002-1.009) \\ \text { Creatinine } & .002 & .121 & 1.004(1.001-1.008) & 1.002(.999-1.005) \\ \text { SFR } & -.002 & .094 & .993(.990-.995) & .997(.994-1) \\ \text { LOS } & -.208 & .038 & .997(.979-1.015) & .971(.946-.998) \\ \text { Supp Oxygen } & 2.03 & <.001^{*} & 12.25(5.94-25.25) & 7.66(3.24-18.10) \\ \text { (Yes) } & & & & \\ \text { CXR } & .461 & .059 & 1.73(1.22-2.46) & 1.585(.981-2.56) \\ \text { Constant } & -7.34 & & & 0(0-0.01)\end{array}$

Model1: Variables initially included: Age, gender, CFS, Comorbidities $>2, N L R, C R P$, creatinine, RR, CPAP, SFR, Total LOS, interaction CPAP*CFS.

Model2: Variables initially included were the same as model $1+$ Supp 02 and CXR.

pseuso $\mathrm{R}_{\text {model } 1}^{2}=25.2 \%$, pseuso $\mathrm{R}_{\text {model } 2}=32.6 \%$ which mean Sup 02 as a significant predictor could explain additional $7.4 \%$ of variance in mortality outcome.

Model 1 cross validation accuracy on test set $=78.3 \%$, AUROC $=.842$.

Model 2 cross validation accuracy on test set $=78.1 \%$, AUROC $=.871$. 
Discussion: This retrospective study identified several risk factors for poor outcomes in hospitalised adults with COVID-19.

The striking observation was the high mortality rate in our cohort, $38 \%$ compared to the national average of $33 \%{ }^{14}$. The plausible explanation is that a large proportion of population in Southend are retired and elderly.

The second key finding was older age with greater frailty scores. There are very few studies which evaluated clinical frailty in patients in COVID -19. Similar to our study, an Italian group assessed frailty, which demonstrated increased in-hospital mortality, ICU admissions, independent of age and Sex ${ }^{15}$. Another study showed that CFS, but not age, remained independently associated with mortality ${ }^{16}$. Frailty is perhaps a syndrome that is characterised by dysregulation of the innate and adaptive immunity that leads to chronic inflammation, reduced physiologic reserve and increased risk of poor health outcomes. Frailty should be considered in risk assessment models in future studies and clinical trials to assess interventions and meaningful outcomes.

There is substantial literature emphasizing the importance of geriatric medicine toward frailty prevention and clinical criteria to rapidly identify those with frailty or pre-frailty ${ }^{17,18}$. The irreversible downward spiralling of frailty will begin, if any acute negative health conditions break the equilibrium. This was clearly reflected in the recent COVID -19 pandemic, particularly in countries such as Italy.

In a prospective study of older patients with community acquired pneumonia, nursing home residency was an independent risk factor for viral pneumonia, which highlights the role of frailty in institutionalised populations ${ }^{19}$ and is associated with worse outcomes in hospitalized older patients ${ }^{20,21}$. The UK NICE guidelines recommend the use of CFS in appropriate patients and states that COVID patients with CFS $>5$, would need to be considered if they were appropriate for critical care management. However, empirical evidence supporting the use of frailty instruments to predict treatment outcomes and triage accordingly is lacking ${ }^{22}$.

Thirdly, our results confirmed that comorbidities, in particular cardiovascular and diabetes were strongly associated with negative outcomes. This is consistent with recent meta-analysis, from CDC China ${ }^{23}$. Similarly, another study of 5700 hospitalised patients with COVID-19 in the New York City area, the most common comorbidities were hypertension (57\%), obesity $(42 \%)$, and diabetes $(34 \%)$ 24 . Of significance, hypertension was reported to increase the odds for death in patients with COVID-19 ${ }^{25,26}$; however we didn't find hypertension to be statistically significant. While hypertension does appear to be associated with more severe disease and increased mortality, there is no strong evidence to indicate increased susceptibility of patients with hypertension to COVID-19 ${ }^{27}$. The mechanisms of this possible relationship and their clinical relevance have been reviewed in a recent statement of the European Society of Hypertension. The putative relationship between hypertension and COVID-19 may relate to the role of ACE $2{ }^{27}$. Diabetes, lung diseases, and obesity, are now well recognised major predictors of poor clinical outcomes. These aspects emphasize the importance of the need for multidisciplinary assessment and treatment, including cardiovascular risk evaluation and therapy, during the course of COVID-19 to reduce mortality.

Data shows European mortality is generally higher in older patients compared to earlier reports from China. Age, as an independent predictor of mortality, was observed in our cohort, which was consistent with the large prospective UK ISARIC study of hospitalised patients ${ }^{14}$ and China ${ }^{28-30}$. In Italian studies, case fatality rates ranged from $35.5 \%$ to $52.5 \%$ in patients aged over 70 years with COVID infection ${ }^{31-34}$. In the USA, older patients aged $\geq 65$ years accounted for higher deaths, with the highest incidence of severe outcomes in patients aged $\geq 85$ years ${ }^{35}$. Why the disease is 
particularly dangerous in older people is not yet known and poorly understood at the molecular level. It is clear, however, that advanced age alone is by far the most significant risk factor, independent of underlying comorbidities ${ }^{36,37}$. An abundance of recent data describing the pathology and molecular changes in COVID-19 patients points to both immunosenescence and inflammaging as major drivers of the high mortality rates in older patients.

In contrast to the literature, male sex was not associated with increased mortality in our study. Large studies from China, Europe and Italy established that males were more susceptible to COVID-19related complications, representing between $50 \%$ and $82 \%$ of the hospitalized patients with COVID $19 \quad 5,8,39$.

We found that baseline CRP, creatinine and NLR were associated with negative impact on mortality. The most consistent prognostic markers in COVID-19 across the different studies were elevated levels of CRP, LDH,Lymphopenia and Neutrophil-to-lymphocyte ratio (NLR), and these appear to stratify patients into higher risk of complications ${ }^{40-42}$. Intriguingly, elevated levels of C-reactive protein appear to be unique to COVID-19 patients when compared to other viral infections. Other consistently reported markers in non-survivors are increased procalcitonin (PCT) and IL-6 levels ${ }^{43}$.

Limitations: The findings of this study are derived from hospitalised cases which might have introduced a bias in disease severity and fatality. The data collection is limited to what is documented in the electronic patient database whether there may be errors both with patient and clinician recall. Our single centre findings may not be generalizable. Routine tests such as LDH, Ferritin, D-Dimer and Troponin could not be carried out on all patients.

\section{Where do we go from here?}

In this large retrospective study, we found that older age, comorbidities, frailty and elevated CRP at admission were significant risk factors for poor outcomes in patients with COVID-19.

Now, more than ever, a holistic approach to patients with comorbidities is required, and rapid solutions to support this must be identified and implemented with urgency. Elderly patients are particularly susceptible to adverse clinical outcomes in COVID - 19 infection and assessment and treatment is challenging. Long-stay residential care homes and hospitals need to urgently design adequate health care plans for elderly patients. Our results strengthen the NICE guidance on the Clinical Frailty Scale, to assist decision-making regarding hospitalization. We suggest integrating the frailty assessment in all COVID-19 patients at hospital admission, which can help clinicians in their decision-making processes. However, shared decision-making is always warranted with respect to personal wishes and preferences of the patient. Given the economic and resource constraints, shifting hospice and palliative care resources to the community was a key message in a recent review to inform practice in the pandemic ${ }^{44}$.

A frailty-based risk-stratification approach, rather than age may prove more valuable when considering interventions in patients with multiple comorbidities. The planning strategies perhaps should include awareness, tools to facilitate communication with healthcare professionals, improved access to institutional health communication and better access to local and social support activities. 
Author Contributions: All authors contributed to data collection, first draft GK, SG and all authors approved final version. Dr GK had full access to all of the data and takes responsibility for the integrity of the data and accuracy of the data analysis. Analysis of the data was performed by $\mathrm{Dr}$ Iman El Sayed.

Conflict of Interest: Dr SG, MD, VW, FH, ID and YA have nothing to disclose. Gouri Koduri reports research support from Roche outside the submitted work.

Funding: None received

\section{References:}

1. Who.int. 2020. WHO Situation Report - 163. [online] Available at: <https://www.who.int/docs/default-source/coronaviruse/situation-reports/20200701-covid-19sitrep-163.pdf?sfursn=c202f05b_2> [Accessed 2 July 2020].

2. Yang J, Zheng Y, Gou X, et al. Prevalence of comorbidities and its effects in coronavirus disease 2019 patients: a systematic review and meta-analysis. Int J Infect Dis. 2020; 94:91-95. [PMC free article] [PubMed] [Google Scholar]

3. Grasselli G, Zangrillo A, Zanella A et al. Baseline characteristics and outcomes of 1591 patients infected with SARS- CoV-2 admitted to ICUs of the Lombardy Region, Italy [e-pub ahead of print]. JAMA https://doi.org/10.1001/jama.2020.5394. Accessed April 7, 2020.

4. Petrilli $C M$, Jones SA, Yang J et al. Factors associated with hospitalization and critical illness among 4,103 patients with COVID-19 disease in New York City [e-pub ahead of print]. medRxiv https://doi.org/10.1101/2020.04.08.20057794. Accessed April 14, 2020.

5. Zhou F, Yu T, Du R et al. Clinical course and risk factors for mortality of adult inpatients with COVID-19 in Wuhan, China: a retrospective cohort study. Lancet 2020; 395:1054-62.

6. Esteban Ortiz-Prado, Katherine Simbaña-Rivera, Lenin Gómez- Barreno et al . Clinical, molecular, and epidemiological characterization of the SARS-CoV-2 virus and the Coronavirus Disease 2019 (COVID-19), a comprehensive literature review. Diagn Microbiol Infect Dis. 2020 Sep; 98(1): 115094. Doi: 10.1016/j.diagmicrobio.2020.115094.

7. Baud D, Qi X, Nielsen-Saines K et al. (2020). Real estimates of mortality following COVID-19 infection. Lancet Infect. Dis. 10.1016/S1473-3099(20)

8. Ruan, S. (2020). Likelihood of survival of coronavirus disease 2019 (comment, published online). Lancet Infectious Diseases, doi: 10.1016/S1473-3099(20)30257-7.

9. Wu Z, McGoogan JM. Characteristics of and important lessons from the coro- navirus disease 2019 (COVID-19) outbreak in China: summary of a report of 72314 cases from the Chinese Center for Disease Control and Prevention. JAMA. 2020; 323(13):1239-1242.

https://doi.org/10.1001/jama.2020.2648 
medRxiv preprint doi: https://doi.org/10.1101/2020.08.13.20163030; this version posted August 14, 2020. The copyright holder for this preprint (which was not certified by peer review) is the author/funder, who has granted medRxiv a license to display the preprint in perpetuity.

All rights reserved. No reuse allowed without permission.

10. Rockwood, K. et al. (2005). A global clinical measure of fitness and frailty in elderly people. CMAJ, 173, 489-495. doi: 10.1503/cmaj.050051

11. Beigel J, Tomashek K, Dodd L et al. Remdesivir for the Treatment of Covid-19 - Preliminary Report. New England Journal of Medicine.

12. Horby PW, Lim W, Emberson J et al. Effect of Dexamethasone in Hospitalized Patients With COVID-19 - Preliminary Report. medRxiv Preprint 2020.

13. Field A. Discovering statistics using IBM SPSS statistics. Sage; 2013

14. Docherty AB, Harrison EM, Green CA, et al. Features of 20133 UK patients in hospital with covid19 using the ISARIC WHO clinical characterisation protocol: prospective observational cohort study. BMJ. 2020 May 22; 369:m1985.

15. Bellelli G, Rebora P, Valsecchi MG et al. Frailty Index Predicts Poor Outcome in COVID-19 Patients. Intensive Care Med 2020.

16. Robert De Smet, Bea Mellaerts, Hannelore Vandewinckele et al. Frailty and mortality in hospitalized older adults with COVID-19: retrospective observational study. J Am Med Dir Assoc. 2020 Jun 9 doi: 10.1016/j.jamda.2020.06.008 [Epub ahead of print]

17. Dent E, Morley JE, Cruz-Jentoft AJ, et al. Physical Frailty: ICFSR International Clinical Practice Guidelines for Identification and Management. J Nutr Health Aging. 2019; 23(9):771-787.

18. Fried LP, Tangen CM, Walston J, et al. Frailty in older adults: evidence for a phenotype. J Gerontol A Biol Sci Med Sci. 2001; 56(3):M146-56.

19. Ma HM, Lee KP, Woo J. Predictors of viral pneumonia: the need for viral testing in all patients hospitalized for nursing home acquired pneumonia. Geriatr Gerontol Int 2013; 13:949-57.

20. Ellis $\mathrm{HL}$, Wan $\mathrm{B}$, Yeung $\mathrm{M}$ et al. Complementing chronic frailty assessment at hospital admission with an electronic frailty index (FI-Laboratory) comprising routine blood test results. CMAJ 2020; 192(1):E3-E8.

21. Muscedere J, Waters B, Varambally A et al. The impact of frailty on intensive care unit outcomes: a systematic review and meta-analysis. Intensive Care Med 2017; 43(8):1105- 1122.

22. Hubbard RE, Maier AB, Hilmer SN et al. Frailty in the Face of COVID-19. Age Ageing 2020.

23. Zhonghua Liu Xing Bing Xue Za Zhi. The epidemiological characteristics of an outbreak of 2019 novel coronavirus diseases (COVID-19) in China]. Epidemiology Working Group for NCIP Epidemic Response, Chinese Center for Disease Control and Prevention.2020 Feb 10; 41(2):145-151.

24. Richardson S, Hirsch JS, Narasimhan M et al. Northwell COVID-19 Research Consortium. Presenting characteristics, Comorbidities, and outcomes among 5700 patients hospitalized With COVID-19 in the New York City area. JAMA 2020;doi:10.1001/jama.2020.6775. 25. Zhou F, Yu T, Du R et al. Clinical course and risk factors for mortality of adult inpatients with COVID-19 in Wuhan, China: a retrospective cohort study. Lancet. 2020 Mar 28; 395(10229):10541062. 
medRxiv preprint doi: https://doi.org/10.1101/2020.08.13.20163030; this version posted August 14, 2020. The copyright holder for this preprint (which was not certified by peer review) is the author/funder, who has granted medRxiv a license to display the preprint in perpetuity.

All rights reserved. No reuse allowed without permission.

26. Guzik T, Mohiddin S, Dimarco A et al. COVID-19 and the cardiovascular system: implications for risk assessment, diagnosis, and treatment options. Cardiovasc Res. 2020 Apr 30: cvaa106. Published online 2020 Apr 30. doi: 10.1093/cvr/cvaa106

27. Kreutz R, Algharably EAE, Azizi $M$ et al. Hypertension, the renin-angiotensin system, and the risk of lower respiratory tract infections and lung injury: implications for COVID-19.Cardiovasc Res. 2020 Apr 15.

28. Guan WJ, Ni ZY, Hu Y et al. Clinical Characteristics of Coronavirus Disease 2019 in China. China Medical Treatment Expert Group for Covid-19. N Engl J Med. 2020 Apr 30; 382(18):1708-1720.

29. Du RH, Liang LR, Yang CQ et al. Predictors of mortality for patients with COVID-19 pneumonia caused by SARS-CoV-2: a prospective cohort study. Eur Respir J 2020; 55: 2000524.

doi:10.1183/13993003.00524-2020

30. Li LQ, Huang T, Wang YQ et al. Novel coronavirus patients' clinical characteristics, discharge rate and fatality rate of meta-analysis. J Med Virol. 2019 doi: 10.1002/jmv.25757.

31.Colaneri M, Sacchi P, Zuccaro V et al. Clinical characteristics of coronavirus disease (COVID-19) early findings from a teaching hospital in Pavia, North Italy, 21 to 28 February 2020. Euro Surveill. 2020 Apr; 25(16).

32. Onder G, Rezza G, Brusaferro $S$. Case-fatality rate and characteristics of patients dying in relation to COVID-19 in Italy. JAMA. 2020 doi: 10.1001/jama.2020.4683.

33. Verity R, O kell C, Dorigattil et al. Estimates of these verity of corona virus disease2019: amodelbased analysis. Lancet Infect Dis. 2020 Mar 30 [Epub ahead of print].

34. Sorbello M, El-Boghdadly K, DiGiacintol et al.The Italian COVID-19 outbreak: experiences and recommendationsfromclinicalpractice.Anaesthesia.2020Jun; 75(6):724-32.

35. CDC COVID-19 Response Team. Severe outcomes among patients with coronavirus disease 2019 (COVID-19): United States, February 12 - March 16, 2020. MMWR Morb Mortal Wkly Rep. 2020 Mar 27; 69(12):343-6.

36. Williamson E, Walker AJ, Bhaskaran KJ et al. Open SAFELY: factors associated with COVID-19related hospital death in the linked electronic health records of 17 million adult NHS patients. medRxiv. 2020.

37. Santesmasses D, Castro JP, Zenin AA et al. COVID-19 is an emergent disease of aging. medRxiv. 2020. 10.1101/2020.04.15.20060095

38. Grasselli G, Zangrillo A, Zanella A et al. Baseline Characteristics and Outcomes of 1591 Patients Infected With SARS-CoV-2 Admitted to ICUs of the Lombardy Region, Italy. JAMA 2020 Apr 6; 323(16):1574-1581.doi: 10.1001/jama.2020.5394.

39. Gebhard C, Regitz-Zagrosek V, Hannelore K et al. Impact of sex and gender on COVID-19 outcomes in Europe. Biol Sex Differ. 2020; 11: 29.Published online 2020 May 25. doi: 10.1186/s13293-020-00304-9 
medRxiv preprint doi: https://doi.org/10.1101/2020.08.13.20163030; this version posted August 14, 2020. The copyright holder for this preprint (which was not certified by peer review) is the author/funder, who has granted medRxiv a license to display the preprint in perpetuity.

All rights reserved. No reuse allowed without permission.

40. Fei J, Fu L, Li Y et al. Reduction of lymphocyte at early stage elevates severity and death risk of COVID-19 patients: a hospital-based case-cohort study. medRxiv. 2020 doi:

41. Wynants L, Van Calster B, Bonten M.M.J et al. Prediction models for diagnosis and prognosis of covid-19 infection: systematic review and critical appraisal. BMJ. 2020; 369:m1328.

42. Zhao X, Zhang B, Li P et al. Incidence, clinical characteristics and prognostic factor of patients with COVID-19: a systematic review and meta-analysis. medRxiv. 2020 doi:

10.1101/2020.03.17.20037572.

43. Huang C, Wang $\mathrm{Y}$, Li X et al. Clinical features of patients infected with 2019 novel coronavirus in Wuhan, China. Lancet 2020;395:497-506

44. Etkind $S$, Bone $A$, Lovell $N$ et al. The role and response of palliative care and hospice services in epidemics and pandemics: a rapid review to inform practice during the COVID-19 pandemic. Journal of Pain and Symptom Management, doi: 10.1016/j.jpainsymman.2020.03.029. 